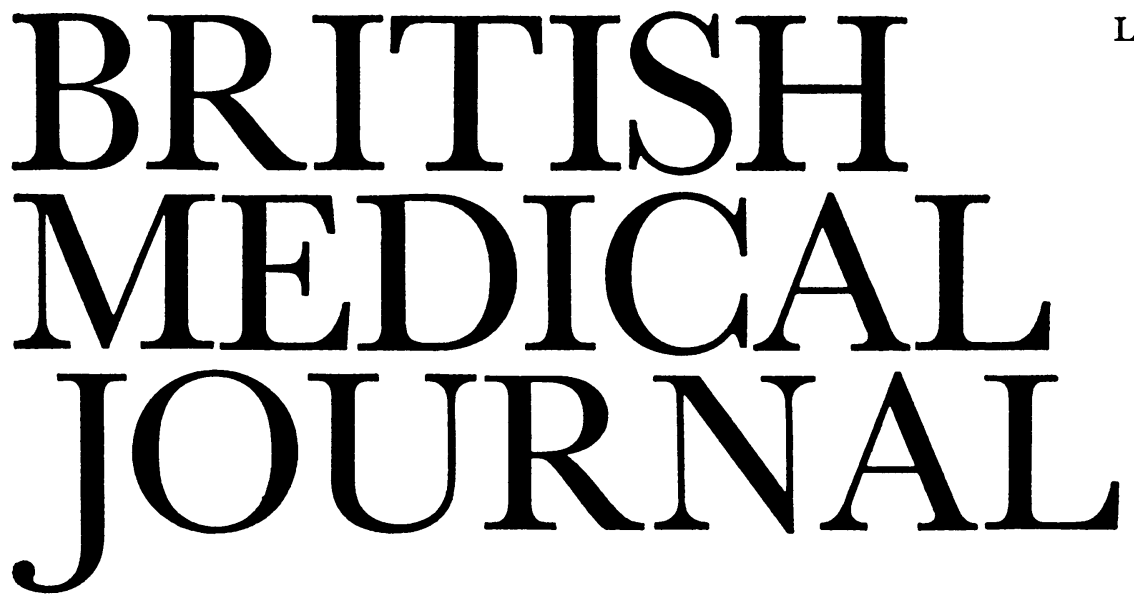

\title{
Cause of Death
}

A single theme runs through the 418 pages of the Brodrick report: ${ }^{1}$ greater accuracy in ascertaining the cause of death. The committee spent six years preparing its report, which ranges widely over the history and purpose of coroners and their inquests, death and cremation certificates, treasure trove, and the design of public mortuaries; but time and again it returns to the central principle, that "the main aim of public policy in all the fields which we have reviewed should be to ensure that the cause of every death is determined and recorded as accurately as possible."

Accurate knowledge of the cause of death is important for two reasons. Firstly, epidemiological and other medical research and the early recognition of new hazards to life such as toxic chemicals and industrial diseases all depend on the cause of every death being determined. Secondly, whenever someone dies in circumstances which might cast blame or suspicion on any person or organization the first step in the investigation must be ascertainment of the cause of death. The report argues that the office of coroner is uniquely suited to the role of responsibility for inquiries of both kinds, accepted as it is by the general public as being impartial and free from pressures of any kind.

For most of the public and many doctors, however, reference of a death to a coroner still implies that there is a suspicion that something may have been wrong-a whiff of doubt. If the Brodrick proposals are to work this misconception will need to be dispelled, for the future role of coroner is seen as establishing the cause of death whenever the attending doctor has not got enough information to be reasonably certain of it. The report suggests that in every case the attending doctor's duty should be to see the body to establish that death has occurred, and then to issue a certificate of the fact and cause of death. If he is a fullyregistered practitioner, has attended the dead person at least once in the seven days preceding death, is confident that he can certify the cause of death with accuracy and precision, and there are no grounds for referring the case to the coroner (see summary of these grounds, p. 499) then this certificate is sent to the registrar. The registrar's disposal certificate is then authority for cremation or burial. If the attending doctor cannot satisfy all the requirements for certifying the cause of death he is required to send the "fact and cause of death" certificate to the coroner, stating his reasons for referral. Normally he would also report the case by telephone.
The report envisages an increase in the number of deaths referred to the coroner. Often, as is the case now, the coroner will arrange for a postmortem examination, and this will give all the information needed. $\mathrm{He}$ would be required to hold an inquest only in cases where homicide was suspected, the body was unidentified, or the dead person had been in legal custody (including compulsory detention in hospital). In all other circumstances the coroner would have complete discretion as to the form of his inquiries. But the greater emphasis on the coroner's part in determining the medical cause of death is balanced in the proposals by a reduction in his public role in the investigation of the facts leading up to death. No longer will the coroner be required to have a jury (though he may still summon one if he thinks there are special reasons to justify it). No longer will there be a verdict; and the sometimes curious riders concocted by coroners' juries will also disappear-but when the coroner's inquiries reveal a hazard to life he will have the right to refer the problem to an appropriate expert or public authority. These changes and others in the coroner's duties and responsibilities are considered in detail by our legal correspondent at p. 498. Clearly, however, one result of this shift in emphasis will be a rise in the number of coroners' necropsies. The report suggests that the provision of pathology services for coroners should become the responsibility of the National Health Service, and that so should the forensic pathology services provided for the police. Responsibility for selecting a pathologist to investigate a particular death would cease to be the coroner's; the report is somewhat vague on this point but suggests the work would be allocated by a senior pathologist or a senior medical administrator. An advantage claimed for this change is that it would encourage investigation of a death by a team of experts instead of a single doctor. Unfortunately for the proposals pathology is one of the branches of the N.H.S. which is already under-staffed, and the committee's bland statement that it "visualizes ... measures ... to secure a sufficiency of pathologists" is to say the least optimistic. One point not mentioned in the report is that two of the traditional financial "perks" for doctors-fees for cremation certificates and fees for coroners' necropsies-seem likely to disappear as a result of its proposals.

Nevertheless, overall the report should be welcomed. It streamlines certification in a sensible manner; it abolishes many of the anachronisms of the coroners' functions; and it 
should provide a basis for the accurate and reliable mortality statistics that are essential as a basis for epidemiological medical research, which seems likely to become of increasing importance in the future.

1 Home Office, Report of the Committee on Death Certification and Coroners. London, H.M.S.O., 1971. Price $£ 2.35$.

\section{Pacemakers for Heart Block}

About 1,800 patients in Britain are at present being treated with implantable cardiac mercury-cell pacemakers. Since pacemakers were first introduced in Sweden and the United States in the late 1950s their reliability has improved, so that implanted models now usually achieve lifetimes of at least two years, with occasional examples exceeding three years. The failure rate within the first year of use is very low, but exhaustion of the mercury cells used to power these devices then becomes increasingly important. ${ }^{1}$

An alternative approach is that pioneered by L. D. Abrams and his colleagues in Birmingham, ${ }^{2}$ who use an implantable receiving coil connected to the heart with an external generator transmitting power across intact skin by induction; about 400 patients are now being treated this way. Clinical results with the two methods are comparable, and the mortality of patients with chronic heart block is approximately $10 \%$ within the first year. ${ }^{3}$ This contrasts with the one-year mortality of $40 \%$ among patients with heart block not related to cardiac infarction, and not induced by drugs, who were treated medically. 56 The improved survival achieved by paced patients is maintained for at least five years, and results are particularly encouraging in patients of working age. ${ }^{7}$

The hospital mortality for pacemaker implantation is about 1 to $3 \%$ whether the electrode is passed to the right ventricle through the venous system or attached surgically to the epicardial surface of the heart. ${ }^{8}$ The indications for pacing are now more numerous than a few years ago, and in many centres in the United States, Canada, France, Germany, and Scandinavia, a pacemaker is always implanted when persistent intermittent or complete heart block has been diagnosed. Since the first Stokes-Adams attack may be fatal there is increasing support in the U.S.A. and parts of Europe for prophylactic implantation in patients with right bundle branch block and left anterior hemiblock, together with delayed conduction in the left posterior fascicle of the conducting system. In the United States approximately 5,000 pacemakers are implanted every month, and about one person in every 5,000 of the population now has one. ${ }^{10}$ This is expected to double within a few years ${ }^{10}$ but is already six times the level in Britain. During 1969 in Sweden initial implantations were carried out in 96 patients per million population, and other Scandinavian countries reached a level of approximately 40 per million. ${ }^{9}$ The equivalent figure in Britain was only 9 per million. ${ }^{4}$ Unless chronic heart block is very much less common in Britain than in other countries it appears that a large number of patients who might benefit from pacemaker therapy are remaining untreated.

It is generally accepted that a recent, proved StokesAdams attack, effort dyspnoea, or frank heart failure due to bradycardia justify pacemaker implantation. Treatment with long-acting isoprenaline has been disappointing, partly be- cause symptoms frequently recur after a short time; though a few patients can be maintained in this way the overall mortality is higher and this approach has been abandoned in many centres. There are no age limits for cardiac pacing, which has been used in young babies and in at least one patient aged 100 years. In many cases chronic heart block is due to fibrosis of conducting tissue without significant muscle damage, ${ }^{11}$ and so patients with a pacemaker can be encouraged to lead normal lives and enjoy leisure activities such as golf or swimming.

The induction type of pacemaker is particularly suitable for young children because only a small receiving coil need be implanted. The most reliable type of implanted pacemaker is still the simple fixed rate unit, but this competes with the normal rhythm in patients with intermittent heart block producing palpitations and occasionally wide variations in blood pressure, which may cause symptoms. Ventricular programmed pacemakers (demand pacemakers) monitor spontaneous cardiac activity and do not stimulate unnecessarily, though their greater complexity results in a shorter battery life. When the batteries of implanted pacemakers near exhaustion, or if one cell fails prematurely, the discharge rate alters; taking the pulse is a simple and informative test provided continuous pacing is present. If spontaneous, non-paced, activity is present an electrocardiogram will usually be required to determine the pacemaker rate. A change of five beats per minute is a sign that the unit should be replaced. When an induction pacemaker is used the external batteries can easily be changed by the patient, and this manoeuvre may have to be performed every two or three weeks with the potential loss of pacing for a few beats on each occasion.

There are a few patients in heart block who manage well without pacing, often for many years, but these are a selected group who have survived the early months, and many have symptoms which restrict their lives. Since a pacemaker might well lessen these restrictions by increasing the ventricular rate its use should always be considered.

\footnotetext{
${ }^{1}$ Harthorne, J. W., Leinbach, R. C., Sanders, C. A., and Austen, W. G., Annals of the New York Academy of Sciences, 1969, 167, 1008.

Abrams, L. D., Hudson, W. A., and Lightwood, R., Lancet, 1960, 1, 1372.

3 Torresani, J., Bernand, Y., Monties, J. R., and Jouve, A., Annals of the New York Academy of Sciences, 1969, 167, 995 .

4 New York Academy of Sciences, 1969, 167, 995. 1971, 20, 295.

4 Sowton, E., Annales de Cardiologie et d'Angiologie, 1971,

' Johansson, B. W., Acta Medica Scandinavica, 1966, 180 . Academy of Sciences, 1964, 3, 835 .

7 Sowton, E., and Flores, J., Bulletin, New York Acad Med., 1971, 47, 999.

${ }^{8}$ Morris, J. D., and Judge, R. D., Annals of the New York Academy of Sciences, 1969, 167, 987.

' Karlof, I., and Lagergren, H., Annales de Cardiologie et d' Angiologie, 1971, 20, 313 .

10 Parsonnet, V., Annales de Cardiologie et d'Angiologie, 1971, 20, 287.

11 Harris, A., Davies, M., Redwood, D., Leatham, A., and Siddons, H., British Heart Fournal, 1969, 31, 206.
}

\section{Neurology of the Leukaemias and Lymphomas}

Though neurological syndromes are a recognized complication in the leukaemias and lymphomas, their precise frequency has been studied relatively rarely. Thus, a recent report by S. Currie and R. A. Henson ${ }^{1}$ has helped to put matters in perspective by clarifying the prevalence of neurological problems in lymphoproliferative and myeloproliferative diseases. 